\title{
BMJ Open Outcomes associated with hospital admissions for accidental opioid overdose in British Columbia: a retrospective cohort study
}

\author{
Richard L Morrow, ${ }^{1}$ Ken Bassett, ${ }^{1,2}$ Malcolm Maclure, ${ }^{1}$ Colin R Dormuth ${ }^{1}$
}

To cite: Morrow RL, Bassett K, Maclure $\mathrm{M}$, et al. Outcomes associated with hospital admissions for accidental opioid overdose in British Columbia: a retrospective cohort study. BMJ Open 2019;9:e025567. doi:10.1136/ bmjopen-2018-025567

- Prepublication history and additional material for this paper are available online. To view these files, please visit the journal online (http://dx.doi. org/10.1136/bmjopen-2018025567).

Received 28 July 2018 Revised 10 January 2019 Accepted 6 March 2019

Check for updates

(c) Author(s) (or their employer(s)) 2019. Re-use permitted under CC BY-NC. No commercial re-use. See rights and permissions. Published by BMJ.

1Department of Anesthesiology, Pharmacology and Therapeutics, University of British Columbia, Vancouver, British Columbia, Canada

${ }^{2}$ Department of Family Practice, University of British Columbia, Vancouver, British Columbia, Canada

Correspondence to

Richard L Morrow;

richard.morrow@ti.ubc.ca

\section{ABSTRACT}

Objectives To study the association between accidental opioid overdose and neurological, respiratory, cardiac and other serious adverse events and whether risk of these adverse events was elevated during hospital readmissions compared with initial admissions.

Design Retrospective cohort study.

Setting Population-based study using linked administrative data in British Columbia, Canada.

Participants The primary analysis included 2433 patients with 2554 admissions for accidental opioid overdose between 2006 and 2015, including 121 readmissions within 1 year of initial admission. The secondary analysis included 538 patients discharged following a total of 552 accidental opioid overdose hospitalizations and 11040 matched controls from a cohort of patients with $\geq 180$ days of prescription opioid use.

Outcome measures The primary outcome was encephalopathy; secondary outcomes were adult respiratory distress syndrome, respiratory failure, pulmonary haemorrhage, aspiration pneumonia, cardiac arrest, ventricular arrhythmia, heart failure, rhabdomyolysis, paraplegia or tetraplegia, acute renal failure, death, a composite outcome of encephalopathy or any secondary outcome and total serious adverse events (all-cause hospitalisation or death). We analysed these outcomes using generalised linear models with a logistic link function.

Results $3 \%$ of accidental opioid overdose admissions included encephalopathy and $25 \%$ included one or more adverse events (composite outcome). We found no evidence of increased risk of encephalopathy (OR $0.57 ; 95 \% \mathrm{Cl} 0.13$ to 2.49 ) or other outcomes during readmissions versus initial admissions. In the secondary analysis, $<5$ patients in each cohort experienced encephalopathy. Risk of the composite outcome (OR 2.15; $95 \% \mathrm{Cl} 1.48$ to 3.12 ) and all-cause mortality (OR 2.13; $95 \% \mathrm{Cl} 1.18$ to 3.86) were higher for patients in the year following overdose relative to controls.

Conclusions We found no evidence that risk of encephalopathy or other adverse events was higher in readmissions compared with initial admissions for accidental opioid overdose. Risk of serious morbidity and mortality may be elevated in the year following an accidental opioid overdose.
Strengths and limitations of this study

A strength is that adverse events associated with accidental opioid overdose were collected from population data rather than adverse event reports.

- This study provides new data to understand the risk of encephalopathy from a larger sample than previously studied.

- The study investigated a wide range of neurological, respiratory, cardiac and other adverse events over a 10-year period.

- Analysis of accidental opioid overdoses was limited to overdoses that led to a hospital admission.

- We controlled for prescription drug use but lacked information on the actual level of drug exposure including illicit drug use.

\section{INTRODUCTION}

A rise in opioid-related deaths in British Columbia (BC) contributed to the declaration of a public health emergency in the province. ${ }^{1}$ Serious morbidity related to opioid overdose, in contrast, has received relatively little attention. The rate of hospitalisations due to opioid overdose in Canada rose by $>30 \%$ from $2007-2008$ to $2014-2015 .^{2}$

Opioid overdose may lead to a range of neurological, respiratory, cardiac or other adverse events. The evidence linking these events to opioid poisoning has primarily, but not exclusively, been limited to case reports. Neurological events include cerebral hypoxia, ${ }^{3-5}$ anoxic encephalopathy, ${ }^{6}$ toxic encephalopathy, ${ }^{7-9}$ delayed encephalopathy $^{10} 11$ and leukoencephalopathy ${ }^{912-14}$ or delayed leukoencephalopathy. ${ }^{15-19}$ Respiratory adverse events include adult respiratory distress syndrome (ARDS), ${ }^{4} 20$ respiratory failure ${ }^{20-22}$ pulmonary haemorrhage ${ }^{21}$ 23-25 and aspiration pneumonia. ${ }^{626} 27$ A retrospective cohort study of opioid overdose leading to intensive care unit admission found that most patients admitted experienced respiratory 
failure requiring mechanical ventilation, approximately $10 \%$ died, and among those who died, half experienced hypoxic brain injury. ${ }^{28}$ Adverse cardiac outcomes may include cardiac arrest, ${ }^{29}{ }^{30}$ ventricular arrhythmia ${ }^{31-33}$ and heart failure. ${ }^{22}{ }^{3435}$ Other adverse effects related to opioid overdose may include rhabdomyolysis, ${ }^{46-40}$ paraplegia or tetraplegia due to spinal cord injury ${ }^{41-43}$ and acute renal failure. ${ }^{4263840}$

We investigated neurological, respiratory, cardiac or other adverse outcomes among patients who were admitted to hospital for accidental opioid poisoning from 2006 to 2015 in BC. Our study examined outcomes that occurred during hospital admissions for accidental opioid poisoning and in the 365 days following discharge from admissions for opioid poisoning. We provide the frequency of these adverse events, assess the influence of repeated overdose and investigate whether risk of these outcomes increased over time. We hypothesised that repeated overdose would show a higher risk of adverse events than initial overdoses due to potential cumulative effects of exposure to high-dose opioids, and that risk of adverse events would increase over the period of our study due to increased use of more potent opioids in BC.

\section{METHODS}

\section{Study setting and design}

We used a retrospective cohort study design to investigate the risk of neurological, respiratory, cardiac and other adverse events during hospital admissions for accidental opioid overdose or in the 1 year following discharge from overdose admissions. The source population for this study consisted of residents of BC who had been registered for provincial medical services for at least 1 year as of any time during 2006-2015.

We investigated outcomes associated with accidental opioid overdose both immediately following an overdose and in the year following an overdose. Our primary analysis focused on outcomes recorded during a hospital admission for an accidental opioid overdose to investigate outcomes immediately following, or shortly after, an overdose. Our secondary analysis focused on outcomes that occurred during the year following discharge from a hospital admission for accidental opioid overdose to investigate events that occurred after a delay following an overdose. Generally, our primary and secondary analyses examined the same neurological, respiratory, cardiac and other adverse events, but in these two different time periods. As described below, however, these two analyses varied in the cohorts studied and the analytical methods used to investigate outcomes.

In our primary analysis, we evaluated whether risk of the study outcomes was increased in repeat admissions for accidental opioid overdose in comparison to initial admissions. For this analysis, we analysed a cohort of patients who had been admitted to hospital during 2006-2015 for an accidental opioid overdose. Accidental opioid overdoses represent a subset of all opioid overdoses, which exclude those identified as resulting from intentional self-harm, therapeutic use (ie, occurred when the drug was used as prescribed) or unknown intent, ${ }^{2}$ as defined by the International Classification of Disease (ICD), version 10 (diagnostic codes for accidental opioid overdose are found in online supplementary appendix table S1). We selected diagnostic codes to identify accidental opioid overdose based on the codes used in a national study by the Canadian Institute for Health Information. ${ }^{2}$ A validation study that tested ICD codes for opioid poisoning in electronic health records reported a positive predictive value of $81 \%$ for opioid overdoses and poisonings, although it did not test all of the codes that we used in our study. ${ }^{44}$ Only patients who had not experienced any of the study outcomes in the year prior to their overdose admission were included in the study, in order to focus on incident outcomes. Patients were excluded if they had received a diagnosis for non-accidental opioid poisoning in the year prior to their overdose admission or a diagnosis of self-harm in their overdose admission or in the previous year, or if they had previously entered long-term or palliative care (diagnostic codes for exclusions are found in online supplementary appendix table S2).

We conducted a secondary analysis to evaluate whether risk of study outcomes was elevated in the year following an accidental opioid overdose. In contrast to our primary analysis, this analysis focused on a cohort of patients with long-term prescription opioid use. From this cohort, we selected patients who had been hospitalised for an accidental opioid overdose and controls who had not experienced an overdose hospitalisation. We defined a cohort of long-term opioid users to include patients with an episode of prescription opioid analgesic therapy lasting $\geq 180$ days during 2006-2014, where an episode was defined by a series of opioid dispensings with no more than 90 days between the end of the days' supply of one script and the beginning of another. Patients were eligible for selection into the 'overdose cohort' or control group on or after the date of their first dispensing of opioid analgesic medication 180 days into an episode of opioid therapy. Patients were no longer eligible for selection into the study cohort after stopping use of opioid pain medication for a period of 90 days. We used a period of 180 days to define long-term therapy to try to ensure that we were including only patients who were taking these medications over an extended period, with the goal of including patients who were as similar as possible in the overdose cohort and control group. We allowed a grace period between the end of one prescription and the start of another to determine the end of therapy, because some patients might take their medication over a longer period than the recorded days' supply. We expected it would be less common for prescriptions to exceed 90 days, and setting the 'grace period' between prescriptions at 90 days assumed that some patients might continue to take their medication for twice that length of time.

In the secondary analysis, patients with long-term prescription opioid use as described above were selected 
to enter the overdose cohort, if they were admitted to hospital for an accidental opioid overdose and had been discharged from hospital during 2006-2014. We selected 20 controls for each member of the overdose cohort, matched on sex and age within 2 years. The date of each overdose patient's discharge from hospital following an overdose admission served as a 'cohort entry date' for the overdose patient and that patient's matched controls. Patients were followed for up to 1 year starting the day after each patient's cohort entry date, and study outcomes were assessed during this follow-up period. Patients could enter the study more than once as a member of the overdose cohort and/or as a control, but it was only possible to enter the overdose cohort more than once if a readmission for accidental opioid overdose occurred at least 1 year from a patient's prior overdose hospitalisation. Patients were excluded if they had received a diagnosis of opioid poisoning, self-harm or any of the study outcomes in the year prior to cohort entry, or if they had previously entered long-term or palliative care. Patients were followed from cohort entry date until the earliest of diagnosis with a relevant study outcome, hospital admission or readmission for opioid poisoning, a diagnosis of self-harm, end of provincial health coverage, entry into long-term or palliative care, death, 365 days of follow-up or 31 December 2015.

\section{Data sources}

We used de-identified, patient-level administrative health data from BC, which were linked with encrypted patient identifiers, to create the study cohorts and conduct analyses. Medical Services Plan (MSP) data included outpatient diagnoses, while the Canadian Institute for Health Information Discharge Abstract Database included hospital admissions and inpatient diagnoses and procedures. MSP registration data were used to determine study eligibility and to define patient demographics. BC PharmaNet data were used to identify a patient's prescription drug use and use of long-term or palliative care drug plans.

\section{Outcome measures}

The primary outcome in our study was encephalopathy, which was defined by an inpatient hospital diagnosis of anoxic brain damage, toxic encephalopathy or unspecified encephalopathy. Secondary outcomes included ARDS, respiratory failure, pulmonary haemorrhage, aspiration pneumonia, cardiac arrest, ventricular arrhythmia, heart failure, rhabdomyolysis, paraplegia or tetraplegia, acute renal failure and death. We also included a composite outcome, which we defined as a diagnosis of encephalopathy and/or any of the secondary outcomes (diagnostic codes for outcomes are found in online supplementary table S3). In our secondary analysis, we added the unplanned outcome of 'serious adverse events', which was defined as hospitalisation or death from any cause, to provide a more comprehensive measure of potential harm. Inpatient hospital data were used to ascertain whether an outcome diagnosis had occurred. Deaths were ascertained with hospital data and MSP registration data.

\section{Covariates}

We adjusted our analyses for patient characteristics, including demographic variables, medical history and prescription history. Demographic variables included sex, age category, low-income status and rural residence. Medical history included variables indicating mental or behavioural disorders due to opioid use, stimulant use and other substance use, and variables for a history of psychiatric illness, pneumonia, other respiratory illness, Romano comorbidity score $(0,1-2, \geq 3)$ and cancer (diagnostic codes for medical covariates are found in online supplementary table S4). Prescription history included a variable indicating past use of high-dose opioid pain medication $(>90 \mathrm{mg}$ of 'oral morphine equivalents' per day, calculated using conversion factors recommended in a recent review of opioid utilisation studies) ${ }^{45}$ a variable for lack of any prescription opioid pain medication use (opioid medications are listed in online supplementary table S5) and a variable for past use of sedative/hypnotic medication (identified by Anatomical Therapeutic Chemical code N05C). In the secondary analysis, the variable for mental and behaviour disorders due to stimulant use was excluded (due to a low prevalence in the control group), and prescription history consisted of variables for high-dose opioid use ( $>90 \mathrm{mg}$ of 'oral morphine equivalents' per day), duration of prescription opioid use $(<1,1$ to $<2,2$ to $<3,3$ to $<4,4$ to $<5$ or $\geq 5$ years $)$ and prior sedative use. We used $90 \mathrm{mg}$ of morphine equivalents per day as a cutoff to define high-dose prescription opioid use, because this reflected advice from the College of Physicians and Surgeons of British Columbia to avoid prescribing of doses above this level in most cases not involving patients with active cancer or those receiving palliative care or end-of-life care. ${ }^{46}$

\section{Statistical analyses}

In the primary analysis, we estimated odds ratios to evaluate whether the risk of each outcome was elevated during repeat hospital admissions for accidental opioid overdose in comparison to initial admissions. We used generalised linear models with a logistic link function and a binomial error distribution. Repeat admissions or 'readmissions' were any admissions for accidental opioid overdose that occurred within a year of a discharge for a previous admission. In the same models, we included a series of binary independent variables indicating the year in which each opioid overdose admission occurred, using the first year of the study, 2006, as a reference year. We inferred the odds of each study outcome occurring in association with an opioid overdose in 2015 in comparison to 2006 (based on the variable indicating an overdose occurred in 2015 versus the reference year), as a test of our hypothesis that the risk of the adverse events we investigated may have increased in recent years due to the use of more potent opioids. In a sensitivity analysis related to the outcome of 
acute kidney failure, we examined trends in diagnosis of acute kidney failure among the general population.

In the secondary analysis, we similarly estimated odds ratios to evaluate whether risk was increased in the 1-year period following a hospital admission for accidental opioid overdose, when compared with controls. The model included a series of binary independent variables for the year in which patients entered the study (according to date of discharge from an overdose patient's overdose admission or corresponding cohort entry date for each control patient), using 2006 as a reference year, to control for timevarying confounding. In additional models, we included interaction terms representing interaction between these 'cohort entry year' variables and a variable indicating whether a patient was in the overdose cohort (the 'exposed' group), as a test for effect measure modification, to investigate whether risk of our study outcomes in the year following opioid overdose was elevated in more recent years.

All regression models used generalised estimating equations to adjust for correlation of observations ('clustering effects') due to multiple observations from the same patients. We had planned to conduct analyses stratified on whether patients had a history of cancer, but due to a smaller than expected sample size, we chose instead to control for cancer as a covariate.

\section{Patient and public involvement}

No patients were involved in setting the research question or the outcome measures, nor were they involved in developing plans for design or implementation of the study. As the study used routinely collected administrative health data, there were no study participants to share results with. There are no plans to disseminate the results of the research to the relevant patient community.

\section{RESULTS}

\section{Patient characteristics}

We identified 3235 patients with a total of 3519 hospital admissions involving accidental opioid overdose during 2006 to 2015. After excluding patients lacking 1 year of provincial medical services coverage prior to admission and applying other exclusion criteria (described above), the cohort for our primary analysis included 2433 patients who had experienced 2554 admissions for accidental opioid overdose, of which 121 were readmissions within a year of a previous admission (table 1). The age of patients at the time of overdose admission ranged from 1 to 99 years (median 48; IQR 32-61 years). Patients who were readmitted tended to have a poorer health status and were more likely to have been diagnosed with opioid use disorder and have used a high-dose prescription opioid.

For the secondary analysis, we identified a cohort of 247883 patients with at least one episode of long-term prescription opioid use during 2006-2014. Our secondary analysis included 538 patients discharged following a total of 552 accidental opioid overdose hospitalisations and 11040 matched controls from the cohort (table 2).
Table 1 Characteristics of patients admitted to hospital for accidental opioid overdose, 2006-2015

\begin{tabular}{lll}
\hline Characteristic & $\begin{array}{l}\text { Admission } \\
\mathbf{n}(\%)\end{array}$ & $\begin{array}{l}\text { Readmission } \\
\mathbf{n}(\%)\end{array}$ \\
\hline Hospitalisations & 2433 & 121 \\
Type of opioid overdose & &
\end{tabular}

Type of opioid overdose

\begin{tabular}{|c|c|c|}
\hline Opium & $8(0.3)$ & 0 \\
\hline Heroin & 419 (17.2) & 15 (12.4) \\
\hline Methadone & 401 (16.5) & $26(21.5)$ \\
\hline Synthetic opioids* & $123(5.1)$ & $7(5.8)$ \\
\hline Other opioids $†$ & $1101(45.3)$ & $46(38.0)$ \\
\hline $\begin{array}{l}\text { Unspecified/other } \\
\text { opioids }\end{array}$ & 515 (21.2) & $34(28.1)$ \\
\hline
\end{tabular}

\begin{tabular}{|c|c|c|}
\hline \multicolumn{3}{|l|}{ Sex } \\
\hline Female & $1134(46.6)$ & $54(44.6)$ \\
\hline Male & 1299 (53.4) & $67(55.4)$ \\
\hline \multicolumn{3}{|l|}{ Age (years) } \\
\hline$<10$ & $36(1.5)$ & 0 \\
\hline $10-19$ & $80(3.3)$ & $<5$ \\
\hline $20-29$ & 371 (15.2) & 16 (13.2) \\
\hline $30-39$ & 411 (16.9) & 19 (15.7) \\
\hline $40-49$ & 415 (17.1) & 15 (12.4) \\
\hline $50-59$ & 477 (19.6) & $21(17.4)$ \\
\hline $60-69$ & 329 (13.5) & $36(29.8)$ \\
\hline $70-79$ & $186(7.6)$ & $10(8.3)$ \\
\hline$\geq 80$ & $128(5.3)$ & $<5$ \\
\hline Low income & 719 (29.6) & 35 (28.9) \\
\hline Rural residence & 325 (13.4) & $17(14.1)$ \\
\hline
\end{tabular}

Substance use disordersł

\begin{tabular}{|c|c|c|}
\hline Opioids & $192(7.9)$ & $25(20.7)$ \\
\hline Sedatives and hypnotics & $22(0.9)$ & $<5$ \\
\hline Stimulants & $112(4.6)$ & $9(7.4)$ \\
\hline Other & 395 (16.2) & 35 (28.9) \\
\hline \multicolumn{3}{|l|}{$\begin{array}{l}\text { Romano comorbidity } \\
\text { scoref }\end{array}$} \\
\hline 0 & $1380(56.7)$ & $54(44.6)$ \\
\hline $1-2$ & $723(29.7)$ & $40(33.1)$ \\
\hline$\geq 3$ & $330(13.6)$ & $27(22.3)$ \\
\hline \multicolumn{3}{|l|}{ Other medical history $\ddagger$} \\
\hline Psychiatric illness & 931 (38.3) & $58(47.9)$ \\
\hline Pneumonia & $224(9.2)$ & 27 (22.3) \\
\hline Other respiratory illness & 473 (19.4) & 35 (28.9) \\
\hline HIV & $42(1.7)$ & $<5$ \\
\hline Hepatitis C & $33(1.4)$ & $<5$ \\
\hline Cancer & $172(7.1)$ & $11(9.1)$ \\
\hline \multicolumn{3}{|l|}{ Opioid prescription history§ } \\
\hline Methadone & $29(1.2)$ & $<5$ \\
\hline Buprenorphine/naloxone & $30(1.2)$ & $<5$ \\
\hline
\end{tabular}

Continued 
Table 1 Continued

\begin{tabular}{|c|c|c|}
\hline Characteristic & $\begin{array}{l}\text { Admission } \\
\text { n (\%) }\end{array}$ & $\begin{array}{l}\text { Readmission } \\
\text { n (\%) }\end{array}$ \\
\hline High-dose opioid for pain & $569(23.4)$ & 33 (27.3) \\
\hline $\begin{array}{l}\text { No use of opioids for } \\
\text { pain }\end{array}$ & 1097 (45.1) & $50(41.3)$ \\
\hline \multicolumn{3}{|l|}{ Other prescription history§ } \\
\hline Sedatives and hypnotics & $571(23.5)$ & $37(30.6)$ \\
\hline Stimulants & $63(2.6)$ & $<5$ \\
\hline
\end{tabular}

Types of opioid overdose correspond to ICD-10 T40.0-T40.4 and T40.6 (some overdoses appear in $>1$ category). Readmissions are defined as additional accidental opioid overdose admissions within 365 days of prior admission.

*Includes buprenorphine, fentanyl, pethidine and tramadol. †Includes codeine, hydromorphone, morphine and oxycodone. $\ddagger$ \#ased on diagnoses at a physician or hospital visit in the 365 days before opioid overdose.

§Based on dispensings in the 180 days prior to opioid overdose. High-dose opioid use is defined by a dispensing of opioid pain medication of $>90$ oral morphine equivalents per day. Small cell sizes are denoted as ' $<5$ ' or 0 as applicable.

Ages ranged from 19 to 100 years (median 58; IQR 49-67 years), as no younger patients met the entry criteria for overdose during long-term prescription opioid use. Patients in the overdose cohort had a poorer health status than controls, and notably many patients had a history of psychiatric illness, high-dose prescription opioid use for pain, prescription opioid use of $\geq 5$ years and/or sedative/hypnotic medication use.

\section{Frequency of adverse events associated with overdose admissions}

The number of hospital admissions for accidental opioid overdose more than doubled over the period of our study, from 180 admissions in 2006 to 393 admissions in 2015, including both initial admissions and readmissions (table 3 ). We found that $3 \%$ of overdose admissions during this 10 -year period included a diagnosis of encephalopathy, and $25 \%$ of overdose admissions included at least one of the adverse outcomes included in our composite outcome (table 3 ).

\section{Adverse events during admissions for accidental opioid overdose}

In our primary analysis, we found no evidence of increased risk of encephalopathy during readmission for accidental opioid overdose in comparison to initial admission for accidental opioid overdose (adjusted OR 0.57; 95\% CI 0.13 to 2.49) (table 4). Women admitted to hospital for accidental opioid overdose had a lower risk of encephalopathy than men (adjusted OR 0.46 ; $95 \%$ CI 0.26 to 0.81 ) (online supplementary appendix table S6). In addition, we observed no increase in risk of either death in hospital or our composite outcome during readmission for accidental opioid overdose, compared with initial admission (adjusted OR 0.86, $95 \%$ CI 0.27 to 2.76, for death in hospital, and adjusted OR
Table 2 Characteristics of patients discharged from hospital after accidental opioid overdose and matched controls among patients with long-term prescription opioid use ( $\geq 180$ days), 2006-2014

\begin{tabular}{|c|c|c|}
\hline & $\begin{array}{l}\text { Overdose } \\
\text { patients } \\
\text { n (\%) }\end{array}$ & $\begin{array}{l}\text { Controls } \\
\text { n (\%) }\end{array}$ \\
\hline Number of patients & 552 & 11040 \\
\hline \multicolumn{3}{|c|}{ Type of opioid overdose } \\
\hline Heroin & $14(2.5)$ & $\mathrm{n} / \mathrm{a}$ \\
\hline Methadone & $43(7.8)$ & $\mathrm{n} / \mathrm{a}$ \\
\hline Synthetic opioids ${ }^{*}$ & $42(7.6)$ & $\mathrm{n} / \mathrm{a}$ \\
\hline Other opioids $†$ & 337 (61.1) & $\mathrm{n} / \mathrm{a}$ \\
\hline $\begin{array}{l}\text { Unspecified/other } \\
\text { opioids }\end{array}$ & 143 (25.9) & $\mathrm{n} / \mathrm{a}$ \\
\hline
\end{tabular}

Sex

\begin{tabular}{|lll|}
\hline $\begin{array}{c}\text { Female } \\
\text { Male }\end{array}$ & $332(60.1)$ & $6640(60.1)$ \\
\hline Age (years) & $220(39.9)$ & $4400(39.9)$ \\
\hline $19-29$ & $14(2.5)$ & $269(2.4)$ \\
\hline $30-39$ & $41(7.4)$ & $829(7.5)$ \\
\hline $40-49$ & $89(16.1)$ & $1771(16.0)$ \\
\hline $50-59$ & $165(29.9)$ & $3296(29.9)$ \\
\hline $60-69$ & $129(23.4)$ & $2562(23.2)$ \\
\hline $70-79$ & $81(14.7)$ & $1611(14.6)$ \\
\hline $80-89$ & $25(4.5)$ & $561(5.1)$ \\
\hline$\geq 90$ & $8(1.4)$ & $141(1.3)$ \\
\hline Low income & $141(25.5)$ & $2607(23.6)$ \\
\hline Rural residence & $95(17.2)$ & $1807(16.4)$ \\
\hline
\end{tabular}

Substance use disorders $\ddagger$

$\begin{array}{lll}\text { Opioids } & 58(10.5) & 81(0.7) \\ \text { Sedatives and hypnotics } & 14(2.5) & 16(0.1) \\ \text { Stimulants } & 17(3.1) & 31(0.3) \\ \text { Other } & 103(18.7) & 284(2.6)\end{array}$

Romano comorbidity
scoreł

$\begin{array}{cll}0 & 202(36.6) & 6038(54.7) \\ 1-2 & 219(39.7) & 3826(34.7) \\ \geq 3 & 131(23.7) & 1176(10.7) \\ \text { Other medical history } \neq & & \\ \text { Psychiatric illness } & 300(54.3) & 2534(23.0) \\ \text { Pneumonia } & 93(16.8) & 405(3.7) \\ \text { Other respiratory illness } & 162(29.3) & 1709(15.5) \\ \text { HIV } & <5 & 56(0.5) \\ \text { Hepatitis C } & 15(2.7) & 27(0.2) \\ \text { Cancer } & 52(9.4) & 822(7.4)\end{array}$

Opioid prescription history§

Methadone $\quad 7(1.3) \quad 20(0.2)$

Continued 
Table 2 Continued

\begin{tabular}{lll}
\hline & $\begin{array}{l}\text { Overdose } \\
\text { patients } \\
\mathbf{n}(\%)\end{array}$ & $\begin{array}{l}\text { Controls } \\
\mathbf{n}(\%)\end{array}$ \\
\hline $\begin{array}{l}\text { Buprenorphine/naloxone } \\
\text { High-dose opioid for }\end{array}$ & $305(55.3)$ & $2152(19.5)$ \\
pain & $<5$ \\
\hline $\begin{array}{l}\text { Duration of prescription opioid use (years) } \\
<1\end{array}$ & $61(11.1)$ & $1876(17.0)$ \\
\hline 1 to $<2$ & $92(16.7)$ & $2362(21.4)$ \\
2 to $<3$ & $53(9.6)$ & $1422(12.9)$ \\
\hline 3 to $<4$ & $47(8.5)$ & $1006(9.1)$ \\
4 to $<5$ & $33(6.0)$ & $797(7.2)$ \\
$\geq 5$ & $266(48.2)$ & $3577(32.4)$ \\
\hline $\begin{array}{l}\text { Other prescription history§ } \\
\text { Sedatives and hypnotics }\end{array}$ & $219(39.7)$ & $2506(22.7)$ \\
\hline Stimulants & $10(1.8)$ & $146(1.3)$ \\
\hline
\end{tabular}

Types of opioid overdose correspond to ICD-10 T40.0-T40.4 and T40.6.

*Includes buprenorphine, fentanyl, pethidine and tramadol. tIncludes codeine, hydromorphone, morphine and oxycodone . $\ddagger$ Based on diagnoses at a physician or hospital visit in the 365 days before follow-up.

$\S$ Based on dispensings in the 180 days prior to follow-up. High-dose opioid use is defined by a dispensing of opioid pain medication of $>90$ oral morphine equivalents per day. Small cell sizes are denoted as ' $<5$ ' or 0 as applicable.

$0.83,95 \%$ CI 0.54 to 1.26 , for the composite outcome). Similarly, results for other secondary outcomes did not indicate any increased risk during readmission for accidental opioid overdose, compared with initial admission (table 4).

We included indicator variables for the year in which each accidental opioid overdose occurred in the regression models for our primary analysis, which provided a test of whether risk of the outcome in each model was higher in the final year of our study (2015) in comparison with the initial year of the study (2006). We found the risk of encephalopathy was not elevated in 2015 in comparison to 2006 (OR $0.73 ; 95 \%$ CI 0.28 to 1.89 ) (table 4 ). In contrast, respiratory failure in association with opioid overdose was approximately three times higher in 2015 in relation to 2006 (OR 3.05; 95\% CI 1.15 to 8.08), although the estimate was imprecise. While no other outcomes showed a significantly higher risk in the last year of the study, the point estimate for risk of acute renal failure was elevated but non-significant (OR 1.86; 95\% CI 0.95 to 3.66). In a sensitivity analysis, an examination of the general trend in incidence of acute renal failure showed a similar elevation in risk of acute renal failure in the general population of $\mathrm{BC}$ (relative risk 2.38; 95\% CI 2.30 to 2.47 ).

\section{Adverse events in year following admissions for accidental opioid overdose}

In our secondary analysis, we compared patients in the year following discharge from an accidental opioid overdose admission to controls, among a cohort of patients with long-term prescription opioid use. Encephalopathy was diagnosed in fewer than five patients in each of the cohorts in our secondary analysis (the overdose cohort and the control cohort), so we could not estimate an OR to compare overdose patients with controls for this outcome. Our analyses suggested a doubling of the odds of experiencing one of the events in our composite outcome (OR 2.15; 95\% CI 1.48 to 3.12 ) or a serious adverse event (OR 1.97; 95\% CI 1.62 to 2.39), or dying from any cause (OR 2.13; $95 \%$ CI 1.18 to 3.86), for patients in the year following a hospital admission for accidental opioid overdose, compared with controls (table 5). Analyses of effect measure modification (not shown) did not indicate that year of cohort entry was an effect modifier in relation to risk of our study outcomes among overdose patients in the year following an overdose relative to control patients.

\section{DISCUSSION}

In our study, we found that encephalopathy was diagnosed in about $3 \%$ of accidental opioid overdose admissions from 2006 to 2015, and at least one of the adverse events in our composite outcome occurred in $25 \%$ of accidental opioid overdose admissions. We found no evidence that risk of encephalopathy or other adverse outcomes was increased in readmissions in comparison to initial admissions for accidental opioid overdose. We found that risk of respiratory failure was elevated in 2015 in relation to 2006. Since reports suggest that more potent prescription and illicit opioids have been used in BC towards the end of our study period, ${ }^{47} 48$ the apparent increase in risk of respiratory failure may reflect exposure to more potent opioids; however, this increase in risk may have occurred due to co-ingestion of other substances ${ }^{28}$ or due to other factors. While the risk of acute renal failure was non-significantly elevated in 2015 compared with 2006, a sensitivity analysis indicated that this may reflect a general trend in diagnosis of acute kidney failure. ${ }^{49}$ Our comparison of overdose patients to controls within a cohort of patients with long-term opioid use suggested that the risk of serious adverse events including respiratory failure and death may be elevated in the year following an accidental opioid overdose.

A potential link between opioid overdose and encephalopathy has been reported in case reports and case series. ${ }^{357-19}$ Additionally, a prospective observational study reported that 1 of 573 patients visiting the emergency department for opioid overdose suffered from cerebral anoxia, ARDS and death, ${ }^{4}$ and a retrospective chart review reported that 2 of 42 ICU patients with heroin overdose suffered from anoxemic encephalopathy and death. ${ }^{6}$ Our finding that $77(3 \%)$ of 2554 admissions related to accidental overdose included a diagnosis of encephalopathy provides additional data on this association.

We included both anoxic brain damage and toxic encephalopathy in the definition of encephalopathy in our study, because case reports raise concerns about a 
Table 3 Number of hospital admissions for accidental opioid overdose and outcomes evaluated during overdose admission, by year

$\begin{array}{lllllllllll}2006 & 2007 & 2008 & 2009 & 2010 & 2011 & 2012 & 2013 & 2014 & 2015 & 2006-2015\end{array}$

\begin{tabular}{|c|c|c|c|c|c|c|c|c|c|c|c|}
\hline \multicolumn{12}{|l|}{ Overdose hospitalisations (n): } \\
\hline Admission & $\sim 178$ & 166 & $\sim 200$ & 211 & 207 & 251 & 274 & 284 & 290 & 372 & 2433 \\
\hline Readmission & $<5$ & 6 & $<5$ & 15 & 8 & 17 & 15 & 18 & 16 & 21 & 121 \\
\hline All & 180 & 172 & 203 & 226 & 215 & 268 & 289 & 302 & 306 & 393 & 2554 \\
\hline \multicolumn{12}{|l|}{ Type of opioid overdose $(n)$ : } \\
\hline Heroin & 28 & 27 & 34 & 28 & 28 & 35 & 35 & 56 & 67 & 96 & 434 \\
\hline Methadone & 30 & 26 & 36 & 32 & 31 & 36 & 54 & 47 & 65 & 70 & 427 \\
\hline Synthetic opioid $\dagger$ & 9 & $<7$ & $<7$ & 8 & 11 & 10 & 14 & 12 & 19 & 37 & 130 \\
\hline Other opioid $\neq$ & 80 & 82 & 81 & 109 & 101 & 135 & 143 & 147 & 121 & 148 & 1147 \\
\hline Unspecified/other & 46 & 41 & 52 & 57 & 53 & 60 & 55 & 56 & 53 & 76 & 549 \\
\hline \multicolumn{12}{|l|}{ Number of outcomes ${ }^{*}(n)$ : } \\
\hline Encephalopathy & 7 & $<5$ & $<5$ & $<5$ & $<5$ & 8 & 14 & 11 & 8 & 17 & 77 \\
\hline Respiratory failure & $<6$ & $<6$ & 7 & 8 & 7 & 10 & 24 & 16 & 17 & 37 & 134 \\
\hline Aspiration pneumonia & 20 & 17 & 18 & 21 & 33 & 31 & 38 & 30 & 36 & 44 & 288 \\
\hline Rhabdomyolysis & 7 & 6 & 10 & 11 & 12 & 10 & 17 & 12 & 19 & 20 & 124 \\
\hline Acute renal failure & 13 & 15 & 9 & 16 & 20 & 25 & 30 & 24 & 34 & 51 & 237 \\
\hline Death in hospital & 8 & $<5$ & 7 & 7 & $<5$ & 7 & 9 & 9 & 12 & 13 & 80 \\
\hline \multicolumn{12}{|l|}{ Composite outcome§ } \\
\hline Admission with $\geq 1$ event & 42 & 37 & 36 & 50 & 54 & 68 & 87 & 72 & 82 & 109 & 637 \\
\hline Total events & 69 & 55 & 62 & 76 & 83 & 108 & 150 & 111 & 142 & 199 & 1055 \\
\hline \multicolumn{12}{|l|}{ Incidence proportion I (\%): } \\
\hline Encephalopathy & 3.9 & $\mathrm{n} / \mathrm{a}$ & $\mathrm{n} / \mathrm{a}$ & $\mathrm{n} / \mathrm{a}$ & $\mathrm{n} / \mathrm{a}$ & 3.0 & 4.8 & 3.6 & 2.6 & 4.3 & 3.0 \\
\hline Respiratory failure & $\mathrm{n} / \mathrm{a}$ & $\mathrm{n} / \mathrm{a}$ & 3.4 & 3.5 & 3.3 & 3.7 & 8.3 & 5.3 & 5.6 & 9.4 & 5.3 \\
\hline Aspiration pneumonia & 11.1 & 9.9 & 8.9 & 9.3 & 15.3 & 11.6 & 13.1 & 9.9 & 11.8 & 11.2 & 11.3 \\
\hline Rhabdomyolysis & 3.9 & 3.5 & 4.9 & 4.9 & 5.6 & 3.7 & 5.9 & 4.0 & 6.2 & 5.1 & 4.9 \\
\hline Acute renal failure & 7.2 & 8.7 & 4.4 & 7.1 & 9.3 & 9.3 & 10.4 & 7.9 & 11.1 & 13.0 & 9.3 \\
\hline Death in hospital & 4.4 & $\mathrm{n} / \mathrm{a}$ & 3.4 & 3.1 & $\mathrm{n} / \mathrm{a}$ & 2.6 & 3.1 & 3.0 & 3.9 & 3.3 & 3.1 \\
\hline \multicolumn{12}{|l|}{ Composite outcome† } \\
\hline Admission with $\geq 1$ event & 23.3 & 21.5 & 17.7 & 22.1 & 25.1 & 25.4 & 30.1 & 23.8 & 26.8 & 27.7 & 24.9 \\
\hline
\end{tabular}

*To avoid small cell sizes, less common types of overdose (opium) and outcome (eg, cardiac outcomes) have been omitted, or a value of '<5' was entered for counts and corresponding proportions were listed as ' $n / a$ '. Where counts $<5$ could be deduced, values of ' $<6$ ' or ' $<7$ ' have been used or a tilde $(\sim)$ was used for approximate values.

†Includes buprenorphine, fentanyl, pethidine and tramadol.

łIncludes codeine, hydromorphone, morphine and oxycodone.

$\S$ The 'composite outcome' included encephalopathy, ARDS, respiratory failure, pulmonary haemorrhage, aspiration pneumonia, cardiac arrest, ventricular arrhythmia, heart failure, rhabdomyolysis, acute renal failure or death ('total events' does not equal the sum of the other events reported, because some outcomes included in the composite outcome were not reported separately).

IIIncidence proportion describes the percentage of hospital admissions for accidental opioid overdose in which patients were diagnosed with each type of outcome in each period.

ARDS, adult respiratory distress syndrome.

potential association between opioid overdose about these outcomes, and these diagnoses describe important brain injuries. ${ }^{6-9}$ In addition, studies that use administrative health data face the limitation that coding of outcomes in the data will often not be precise, so we have included unspecified encephalopathy in the outcome definition. There is a lack of validation studies for either anoxic or toxic encephalopathy, so the specificity of the individual diagnostic codes we used and of our composite outcome is unknown. Inclusion of unspecified encephalopathy may lead to some outcome misclassification, but this definition will have a greater sensitivity to detect encephalopathy when it has occurred. It is expected that any outcome misclassification would be similar across exposure groups in our primary analysis (ie, during an initial or repeat admission for accidental opioid overdose). This type of 
Table 4 Influence of readmission for accidental opioid overdose and year of overdose on neurological, respiratory, cardiac and other outcomes evaluated during overdose admission

\begin{tabular}{lllll} 
& \multicolumn{2}{l}{ Opioid overdose readmission } & & \multicolumn{2}{l}{ Admissions in 2015 versus 2006* } \\
\cline { 2 - 3 } \cline { 5 - 6 } Events & Crude OR & $\begin{array}{l}\text { Adjusted OR } \\
(95 \% \mathrm{Cl})\end{array}$ & Crude OR & $\begin{array}{l}\text { Adjusted OR } \\
(95 \% \mathrm{Cl})\end{array}$
\end{tabular}

\begin{tabular}{|c|c|c|c|c|c|}
\hline \multicolumn{6}{|l|}{ Primary outcome } \\
\hline \multicolumn{6}{|l|}{ Neurological: } \\
\hline Encephalopathy & 77 & 0.52 & 0.57 (0.13 to 2.49 ) & 1.12 & $0.73(0.28$ to 1.89$)$ \\
\hline \multicolumn{6}{|l|}{ Secondary outcomes } \\
\hline \multicolumn{6}{|l|}{ Respiratory outcomes: } \\
\hline Respiratory failure & 134 & 1.10 & 0.93 (0.43 to 2.04$)$ & 3.65 & $3.05(1.15$ to 8.08$)$ \\
\hline Aspiration pneumonia & 288 & 0.45 & 0.48 (0.21 to 1.08$)$ & 1.01 & $0.88(0.49$ to 1.59$)$ \\
\hline ARDS & 19 & $\mathrm{n} / \mathrm{a}$ & $\mathrm{n} / \mathrm{a}$ & $\mathrm{n} / \mathrm{a}$ & $\mathrm{n} / \mathrm{a}$ \\
\hline Pulmonary haemorrhage & $<5$ & $\mathrm{n} / \mathrm{a}$ & $\mathrm{n} / \mathrm{a}$ & $\mathrm{n} / \mathrm{a}$ & $\mathrm{n} / \mathrm{a}$ \\
\hline \multicolumn{6}{|l|}{ Cardiac outcomes: } \\
\hline Cardiac arrest & 56 & $\mathrm{n} / \mathrm{a}$ & $\mathrm{n} / \mathrm{a}$ & $\mathrm{n} / \mathrm{a}$ & $\mathrm{n} / \mathrm{a}$ \\
\hline Ventricular arrhythmia & 5 & $\mathrm{n} / \mathrm{a}$ & $\mathrm{n} / \mathrm{a}$ & $\mathrm{n} / \mathrm{a}$ & $\mathrm{n} / \mathrm{a}$ \\
\hline Heart failure & 28 & $\mathrm{n} / \mathrm{a}$ & $\mathrm{n} / \mathrm{a}$ & $\mathrm{n} / \mathrm{a}$ & $\mathrm{n} / \mathrm{a}$ \\
\hline \multicolumn{6}{|l|}{ Other outcomes: } \\
\hline Rhabdomyolysis & 124 & 0.64 & 0.64 (0.24 to 1.75$)$ & 1.33 & $0.96(0.38$ to 2.43$)$ \\
\hline Acute renal failure & 237 & 1.13 & 1.07 (0.60 to 1.91$)$ & 1.97 & $1.86(0.95$ to 3.66$)$ \\
\hline Paraplegia or tetraplegia & 6 & $\mathrm{n} / \mathrm{a}$ & $\mathrm{n} / \mathrm{a}$ & $\mathrm{n} / \mathrm{a}$ & $\mathrm{n} / \mathrm{a}$ \\
\hline Death in hospital & 80 & 0.77 & 0.86 (0.27 to 2.76$)$ & 0.74 & $0.63(0.24$ to 1.65$)$ \\
\hline Composite outcome $†$ & 637 & 0.82 & 0.83 (0.54 to 1.26$)$ & 1.27 & $1.08(0.71$ to 1.64$)$ \\
\hline
\end{tabular}

OR estimates have been omitted, and replaced with 'n/a' for 'not available', for outcomes where estimation was not possible due to a small number of events in one or more exposure groups.

*The 'Admissions in 2015 versus 2006' column reports the odds of each outcome occurring in association with an accidental opioid overdose hospitalisation in 2015 when compared with 2006.

†The 'composite outcome' was defined as the occurrence of one or more of the following within an admission: encephalopathy, ARDS, respiratory failure, pulmonary haemorrhage, aspiration pneumonia, cardiac arrest, ventricular arrhythmia, heart failure, rhabdomyolysis, acute renal failure or death (corresponds to 'admission with $\geq 1$ event' under the composite outcome in table 3). Occurrences of the composite outcome do not equal the sum of other events, because some admissions included more than onetype of event but this only counted once towards the composite outcome.

ARDS, adult respiratory distress syndrome.

misclassification could bias the analysis towards a null effect. $^{50}$

The association between respiratory failure and accidental opioid overdose in our study appears to be consistent with a recent US study. While not directly reporting on respiratory failure, the US study found that $10.0 \%$ of emergency department visits for opioid overdose were associated with mechanical ventilation. ${ }^{51}$ Our hospital admission data found that respiratory failure occurred in $9.4 \%$ of overdose admissions in 2015. In addition, a cohort study of 178 adults with opioid overdose leading to intensive care unit admission reported that $84.8 \%$ required mechanical ventilation. ${ }^{28}$

Our study provides new data on potential association between accidental opioid overdose and a range of serious adverse events. A strength of our study was that adverse events associated with overdose were collected from population data rather than adverse event reports. These data were more comprehensive than adverse event reports, because the data were collected routinely by the healthcare system rather than relying on reports from the public, healthcare providers or manufacturers and because the data available covered most of the population of the province. However, our study had some limitations. Our analysis of readmissions which occurred within 1 year of a previous admission excluded patients with adverse events in the year prior to readmission. However, this exclusion may have created selection bias by excluding patients who were more susceptible to these adverse events from the cohort of readmission patients. In addition, we analysed data on accidental opioid hospitalisations but lacked data about overdoses that did not result in a hospital admission and lacked complete information about drug exposure including illicit drug use. We included patients with long-term use of prescription opioids in our secondary analysis based on the information in available administrative health databases; however, this excluded others with long-term opioid use who lacked ongoing prescriptions 
Table 5 Risk of neurological, respiratory, cardiac and other outcomes in 1 year following hospital admission for accidental opioid overdose in comparison to controls among patients with long-term prescription opioid use ( $\geq 180$ days)

\begin{tabular}{lllll} 
Events & & & \multicolumn{2}{c}{ Odds ratios } \\
\cline { 1 - 2 } $\begin{array}{l}\text { Overdose } \\
\text { patients } \\
(n=552)\end{array}$ & $\begin{array}{l}\text { Controls } \\
(n=11040)\end{array}$ & & Crude & $\begin{array}{l}\text { Adjusted } \\
(95 \% \mathrm{Cl})\end{array}$
\end{tabular}

Primary outcome

Neurological:

\begin{tabular}{|c|c|c|c|c|}
\hline Encephalopathy & $<5$ & $<5$ & $\mathrm{n} / \mathrm{a}$ & $\mathrm{n} / \mathrm{a}$ \\
\hline \multicolumn{5}{|l|}{ Secondary outcome } \\
\hline \multicolumn{5}{|l|}{ Respiratory outcomes: } \\
\hline Respiratory failure & 14 & 23 & 12.46 & 6.21 (2.24 to 17.21$)$ \\
\hline Aspiration pneumonia & 5 & 19 & 5.30 & 2.96 (0.90 to 9.71$)$ \\
\hline ARDS & $<5$ & 9 & $\mathrm{n} / \mathrm{a}$ & $\mathrm{n} / \mathrm{a}$ \\
\hline Pulmonary haemorrhage & 0 & 0 & $\mathrm{n} / \mathrm{a}$ & $\mathrm{n} / \mathrm{a}$ \\
\hline \multicolumn{5}{|l|}{ Cardiac outcomes: } \\
\hline Cardiac arrest & 0 & 5 & $\mathrm{n} / \mathrm{a}$ & $\mathrm{n} / \mathrm{a}$ \\
\hline Ventricular arrhythmia & 0 & 5 & $\mathrm{n} / \mathrm{a}$ & $\mathrm{n} / \mathrm{a}$ \\
\hline Heart failure & 9 & 95 & 1.93 & 0.99 (0.45 to 2.15$)$ \\
\hline \multicolumn{5}{|l|}{ Other outcomes: } \\
\hline Rhabdomyolysis & 5 & 19 & 5.30 & 3.08 (0.87 to 10.88$)$ \\
\hline Acute renal failure & 16 & 103 & 3.18 & 1.66 (0.90 to 3.05$)$ \\
\hline Paraplegia or tetraplegia & $<5$ & 6 & $\mathrm{n} / \mathrm{a}$ & $\mathrm{n} / \mathrm{a}$ \\
\hline All-cause mortality & 22 & 96 & 4.73 & 2.13 (1.18 to 3.86$)$ \\
\hline Composite outcome* & 59 & 309 & 4.14 & 2.15 (1.48 to 3.12$)$ \\
\hline Serious adverse events $\dagger$ & 315 & 3489 & 2.84 & 1.97 (1.62 to 2.39$)$ \\
\hline
\end{tabular}

OR estimates have been omitted, and replaced with 'n/a' for 'not available', for outcomes where estimation was not possible due to a small number of events in one or more exposure groups.

*The 'composite outcome' was defined as an inpatient hospital diagnosis of one or more of the following: encephalopathy, ARDS, respiratory failure, pulmonary haemorrhage, aspiration pneumonia, cardiac arrest, ventricular arrhythmia, heart failure, rhabdomyolysis, acute renal failure or death.

†Serious adverse events were defined as all-cause hospitalisation or death.

ARDS, adult respiratory distress syndrome.

of their own but used opioids prescribed to others and/ or non-prescription opioids. Lastly, our analyses may have been subject to unmeasured confounders, such as co-ingestion of other drugs with opioids.

\section{CONCLUSIONS}

We found no increased risk of encephalopathy or other adverse events in repeat hospital admissions compared with initial admission for accidental opioid overdose. Our analysis suggests that accidental opioid overdoses were associated with risk of respiratory failure, and that risk of respiratory failure associated with opioid overdose was higher in 2015 compared with 2006. The risk of serious adverse events including respiratory failure and death may be elevated in the year following an accidental opioid overdose.

Acknowledgements The authors thank Mikhail Torban (BC Ministry of Health) and Kenneth Tupper (advised while at the British Columbia Ministry of Health, now at the British Columbia Centre on Substance Use), who provided ideas and feedback during the development of the research protocol, and Tom Perry (Therapeutics
Initiative, University of British Columbia) for feedback on the research protocol and interpretation of results.

Contributors RLM, CRD and KB contributed to the study design. RLM conducted the data analysis and drafted the manuscript. All authors (RLM, KB, MM and CRD) contributed to the interpretation of the data, revised the work for important intellectual content, provided final approval for the version to be published and agree to be accountable for all aspects of the work in ensuring that questions related to the accuracy or integrity of any part of the work are appropriately investigated and resolved.

Funding This work was supported by a 5-year renewable grant to the University of British Columbia from the British Columbia Ministry of Health. Individuals employed by the Ministry of Health at the time the research project was planned provided ideas and feedback on development of the research protocol.

Disclaimer The analyses and interpretations in this study are those of the authors and do not reflect the opinions or policies of the Ministry of Health.

Competing interests None declared.

Patient consent for publication Not required.

Ethics approval The study was approved by the University of British Columbia Clinical Research Ethics Board.

Provenance and peer review Not commissioned; externally peer reviewed. 
Data sharing statement The authors do not have permission to share data from this study.

Open access This is an open access article distributed in accordance with the Creative Commons Attribution Non Commercial (CC BY-NC 4.0) license, which permits others to distribute, remix, adapt, build upon this work non-commercially, and license their derivative works on different terms, provided the original work is properly cited, appropriate credit is given, any changes made indicated, and the use is non-commercial. See: http://creativecommons.org/licenses/by-nc/4.0/.

\section{REFERENCES}

1. Government of British Columbia. Provincial health officer declares public health emergency 2016. 2016. https://news.gov.bc.ca/ releases/2016HLTH0026-000568

2. Canadian Centre for Health Information. Canadian Centre on Substance Abuse. Hospitalizations and emergency department visits due to opioid poisoning in Canada. Ottawa, ON: ClHI, 2016.

3. Voigt I. Fatal overdose due to confusion of an transdermal fentanyl delivery system. Case Rep Crit Care 2013;2013:1-3.

4. Etherington J, Christenson J, Innes G, et al. Is early discharge safe after naloxone reversal of presumed opioid overdose? CJEM 2000;2:156-62.

5. Vila N, Chamorro A. Ballistic movements due to ischemic infarcts after intravenous heroin overdose: report of two cases. Clin Neurol Neurosurg 1997;99:259-62.

6. Grigorakos L, Sakagianni K, Tsigou E, et al. Outcome of acute heroin overdose requiring intensive care unit admission. $J$ Opioid Manag 2010;6:227-31.

7. Morales Odia Y, Jinka M, Ziai WC. Severe leukoencephalopathy following acute oxycodone intoxication. Neurocrit Care 2010:13:93-7.

8. Mills F, MacLennan SC, Devile CJ, et al. Severe cerebellitis following methadone poisoning. Pediatr Radiol 2008;38:227-9.

9. Anselmo M, Campos Rainho A, do Carmo Vale M, et al. Methadone intoxication in a child: toxic encephalopathy? J Child Neurol 2006;21:618-20.

10. Zanin A, Masiero S, Severino MS, et al. A delayed methadone encephalopathy: clinical and neuroradiological findings. $J$ Child Neurol 2010;25:748-51.

11. Shimizu F, Kawai M, Ogasawara J, et al. [Delayed encephalopathy following acute fentanyl intoxicication]. Rinsho Shinkeigaku 2007;47:222-5.

12. Bellot $B$, Michel $F$, Thomachot $L$, et al. Acute leukoencephalopathy after buprenorphine intoxication in a 2-year-old child. European $J$ Paediatr Neurol 2011;15:368-71.

13. Nanan R, von Stockhausen HB, Petersen B, et al. Unusual pattern of leukoencephalopathy after morphine sulphate intoxication. Neuroradiology 2000;42:845-8.

14. Foy L, Seeyave DM, Bradin SA. Toxic leukoencephalopathy due to transdermal fentanyl overdose. Pediatr Emerg Care 2011;27:854-6.

15. Salazar R, Dubow J. Delayed posthypoxic leukoencephalopathy following a morphine overdose. J Clin Neurosci 2012;19:1060-2.

16. Molloy S, Soh C, Williams TL. Reversible delayed posthypoxic leukoencephalopathy. AJNR Am J Neuroradiol 2006;27:1763-5.

17. Shprecher DR, Flanigan KM, Smith AG, et al. Clinical and diagnostic features of delayed hypoxic leukoencephalopathy. $J$ Neuropsychiatry Clin Neurosci 2008;20:473-7.

18. Barnett MH, Miller LA, Reddel SW, et al. Reversible delayed leukoencephalopathy following intravenous heroin overdose. J Clin Neurosci 2001;8:165-7.

19. Pirompanich $\mathrm{P}$, Chankrachang S. Intravenous heroin-associated delayed spongiform leukoencephalopathy: case report and reviews of the literature. J Med Assoc Thai 2015;98:703-8.

20. Pichot $\mathrm{C}$, Petitjeans F, Ghignone M, et al. Swift recovery of severe acute hypoxemic respiratory failure under non-invasive ventilation. Anaesthesiol Intensive Ther 2015;47:138-42.

21. Cole JB, Dunbar JF, Mclntire SA, et al. Butyrfentanyl overdose resulting in diffuse alveolar hemorrhage. Pediatrics 2015;135:e74 $0-\mathrm{e} 743$.

22. Liu SS, Kovell LC, Horne A, et al. A novel case of transient right ventricular failure in a patient with respiratory distress. $J$ Intensive Care Med 2013;28:185-8.

23. Ruzycki S, Yarema M, Dunham M, et al. Intranasal Fentanyl Intoxication Leading to Diffuse Alveolar Hemorrhage. J Med Toxicol 2016;12:185-8.
24. Porter R, O'Reilly H. Pulmonary hemorrhage: a rare complication of opioid overdose. Pediatr Emerg Care 2011;27:742-4.

25. Chaturvedi AK, Rao NG, Baird JR. A death due to self-administered fentanyl. J Anal Toxicol 1990;14:385-7.

26. Eizadi-Mood N, Yaraghi A, Sharifian Z, et al. Clinical presentation and the outcome of therapy in a cohort of patients with methadone toxicity in Iran. Mater 2015;27:276-9.

27. Shadnia S, Faiaz-Noori M-R, Pajoumand A, et al. A case report of opium body packer; review of the treatment protocols and mechanisms of poisoning. Toxicol Mech Methods 2007;17:205-14.

28. Pfister GJ, Burkes RM, Guinn B, et al. Opioid overdose leading to intensive care unit admission: Epidemiology and outcomes. J Crit Care 2016;35:29-32.

29. Nielsen K, Nielsen SL, Siersma V, et al. Treatment of opioid overdose in a physician-based prehospital EMS: frequency and long-term prognosis. Resuscitation 2011;82:1410-3.

30. Boyd JJ, Kuisma MJ, Alaspää AO, et al. Outcome after heroin overdose and cardiopulmonary resuscitation. Acta Anaesthesiol Scand 2006;50:1120-4.

31. Ray WA, Chung CP, Murray KT, et al. Out-of-hospital mortality among patients receiving methadone for noncancer pain. JAMA Intern Med 2015;175:420-7.

32. Butler B, Rubin G, Lawrance A, et al. Estimating the risk of fatal arrhythmia in patients in methadone maintenance treatment for heroin addiction. Drug Alcohol Rev 2011;30:173-80.

33. Daubin C, Quentin C, Goullé JP, et al. Refractory shock and asystole related to tramadol overdose. Clin Toxicol 2007;45:961-4.

34. Garrett PM. Tramadol overdose and serotonin syndrome manifesting as acute right heart dysfunction. Anaesth Intensive Care 2004;32:575-7.

35. Mitchell Heggs L, Genée O, Fichet J. Bi-ventricular failure following methadone overdose. Intensive Care Med 2008;34:1553-4.

36. Melandri R, Re G, Lanzarini C, et al. Myocardial damage and rhabdomyolysis associated with prolonged hypoxic coma following opiate overdose. J Toxicol Clin Toxicol 1996;34:199-203.

37. Zele I, De Tommaso I, Melandri R, et al. [Rhabdomyolysis during acute poisoning with drugs and narcotics. Experience with 7 clinical cases]. Minerva Med 1992;83:847-52.

38. Sahni V, Garg D, Garg S, et al. Unusual complications of heroin abuse: Transverse myelitis, rhabdomyolysis, compartment syndrome, and ARF. Clin Toxicol 2008;46:153-5.

39. Pascual Calvet J, Pou A, Pedro-Botet J, et al. [Non-infective neurologic complications associated to heroin use]. Arch Neurobiol 1989;52(Suppl 1):155-61.

40. Rice EK, Isbel NM, Becker GJ, et al. Heroin overdose and myoglobinuric acute renal failure. Clin Nephrol 2000;54:449-54.

41. Kumar R, West DM, Jingree M, et al. Unusual consequences of heroin overdose: rhabdomyolysis, acute renal failure, paraplegia and hypercalcaemia. Br J Anaesth 1999;83:496-8.

42. Riva N, Morana P, Cerri F, et al. Acute myelopathy selectively involving lumbar anterior horns following intranasal insufflation of ecstasy and heroin. J Neurol Neurosurg Psychiatry 2007;78:908-9.

43. Sahni V, Garg D, Garg S, et al. Unusual complications of heroin abuse: transverse myelitis, rhabdomyolysis, compartment syndrome, and ARF. Clin Toxicol 2008;46:153-5.

44. Green CA, Perrin NA, Janoff SL, et al. Assessing the accuracy of opioid overdose and poisoning codes in diagnostic information from electronic health records, claims data, and death records. Pharmacoepidemiol Drug Saf 2017;26:509-17.

45. Nielsen S, Degenhardt L, Hoban B, et al. A synthesis of oral morphine equivalents (OME) for opioid utilisation studies. Pharmacoepidemiol Drug Saf 2016;25:733-7.

46. College of Physicians and Surgeons of British Columbia. Professional standards and guidelines: Safe prescribing of drugs with potential for misuse/diversion, 2016.

47. Smolina K, Gladstone E, Morgan SG. Determinants of trends in prescription opioid use in British Columbia, Canada, 2005-2013. Pharmacoepidemiol Drug Saf 2016;25:553-9.

48. British Columbia Coroners Service. Illicit drug overdose deaths in BC. Burnaby, BC, 2017.

49. Siew ED, Davenport $A$. The growth of acute kidney injury: a rising tide or just closer attention to detail? Kidney Int 2015;87:46-61.

50. Rothman KJ, Greenland S, Lash TL. Validity in epidemiologic studies. Modern epidemiology. 3rd ed. Philadelphia: Lippincott Williams \& Wilkins, 2008:128-47.

51. Hasegawa K, Brown DF, Tsugawa Y, et al. Epidemiology of emergency department visits for opioid overdose: a populationbased study. Mayo Clin Proc 2014;89:462-71. 